AGRITECH, Vol. 37, No. 2, Mei 2017, Hal. 215-219

DOI: http://doi.org/10.22146/agritech.16747

ISSN 0216-0455 (Print), ISSN 2527-3825 (Online)

Tersedia online di https://jurnal.ugm.ac.id/agritech/

\title{
Analisis Neraca Air Lahan pada Jenis Tanah yang Berkembang pada Daerah Karts di Kecamatan Parigi Kabupaten Muna Sulawesi Tenggara
}

\author{
The Analysis of Soil Water Balance to The Type of Soil that Developing at Karts Area in Village Parigi District Muna \\ Southeast Sulawesi
}

\author{
M. Tufaila1', La Mpia', Jufri Karim² \\ ${ }^{1}$ Jurusan Agroteknologi, Fakultas Pertanian Univeristas Halu Oleo Kampus Bumi Tridharma Anduonohu, \\ Kendari 93232, Indonesia \\ ${ }^{2}$ Jurusan Geografi, Fakultas Ilmu dan Teknologi Kebumian, \\ Univeristas Halu Oleo Kampus Bumi Tridharma Anduonohu, Kendari 93232, Indonesia \\ Email: la_mpia@yahoo.com
}

Submisi: 15 Maret 2016; Penerimaan: 1 Juni 2016

\begin{abstract}
ABSTRAK
Neraca air lahan menggambarkan kondisi air pada suatu wilayah. Perbedaan kondisi iklim dan karateristik lahan memberikan pengaruh terhadap nerca air lahan. Tujuan penelitiaan ini yaitu untuk mengetahui neraca air lahan pada jenis tanah yang berkembang pada bahan induk karts. Kecamatan Parigi Kabupaten Muna memiliki luas 16.245,88 ha terdiri dari jenis tanah Iceptisol, Mollisol, dan Andisol dan berkembang pada formasi geologi Qal dan Qpw. Hasil penelitiaan menunjukan bahwa surpulus air hujan terjadi pada bulan Februari, Maret dan April, sedangkan divisit air terjadi pada bulan Januari, Mei, Juni, Juli, Agustus, September, Oktober, November, dan Desember. Neraca air lahan dilokasi penelitian dipengaruhi oleh iklim, kondisi lahan, dan karateristik tanah. Tanah yang terbentuk diatas batuan karts memberikan pengaruh yang kecil terhadap neraca air lahan.
\end{abstract}

Kata kunci: Formasi geologi; jenis tanah; neraca air lahan

\begin{abstract}
Soil water balance is describes the condition of the water in an area. The difference of climatic conditions and land characteristic denotes the effect of the soil water balance. The objective of this study is to determine soil water balance on the type of soil that developed at parent material karts. Village Parigi district Muna has an area of 16245.88 ha consists of Inceptisol, Mollisol, and Andosol and developing in Qal and Qpw geological formation. The results of research showed that surplus on rainwater occurred in February, March, and April. While the water deficit occurred in January, May, June, July, August, September, October, November, and December. Soil water balance in the research site was affected by climate, soil condition, and soil characteristic. Soil was formed above the karst rock showing little effect on the soil water balance.
\end{abstract}

Keywords: Geological formation; soil type; soil water balance 


\section{PENDAHULUAN}

Neraca air merupakan model hubungan kuantitatif antara jumlah air yang tersedia di atas dan di dalam tanah dengan jumlah curah hujan yang jatuh pada luasan dan kurun waktu tertentu (Noah dkk., 2010). Ketersediaan sumberdaya air sangat dipengaruhi oleh kondisi iklim, topografi, jenis tanah, tutupan lahan serta struktur geologi suatu daerah (Soldevilla-Martineza dkk., 2013). Tingkat ketersediaan air tanah diperoleh dengan menganalisa data kandungan air tanah. Perbedaan jenis tanah dapat mempengaruhi ketersediaan kandungan air tanah (Zappa dan Gurtz, 2003).

Kemampuan tanah menahan air menurut ThornthwaiteMather (1957) sangat ditentukan oleh jenis tanah (terutama tekstur) dan jenis vegetasinya. Vegetasi yang jenisnya sama apabila tumbuh pada jenis tanah yang berbeda, maka akan mempunyai kedalaman zona perakarannya yang berbeda, sehingga nilai Water Holding Capacity (WHC) atau kapasitas lengas tanahnya juga berbeda (Zappa dan Gurtz, 2003).

Karst adalah suatu daerah yang memiliki sistem bentuk lahan dan hidrologi yang khas dan terbentuk dari batuan dengan daya larut yang tinggi serta berkembangnya porositas sekunder dengan baik (Jim dan Dave, 2012). Sistem hidrologi karst menjadikan minimnya akumulasi cadangan air permukaan yang dapat dimanfaatkan. Salah satu permasalahan daerah karts yaitu banyaknya jalur-jalur aliran air dibawah tanah yang sulit dimanfaatkan oleh tanaman (Djakamihardja dan Dedi, 2013).

Kecamatan Parigi Kabupaten Muna memiliki luas 16.245,88 Ha terdiri dari jenis tanah Iceptisol, Mollisol dan Andisol. Daerah ini berkembang pada formasi geologi Qal dan Qpw (Effendi dkk.,1995) dengan penggunaan lahan yaitu penggunaan hutan, kebun campuran, jambu mete, sawah tadah hujan, semak belukar, tegalan, dan bakau. Tujuan penelitiaan ini yaitu untuk mengetahui neraca air lahan pada jenis tanah yang berkembang pada bahan induk karts.

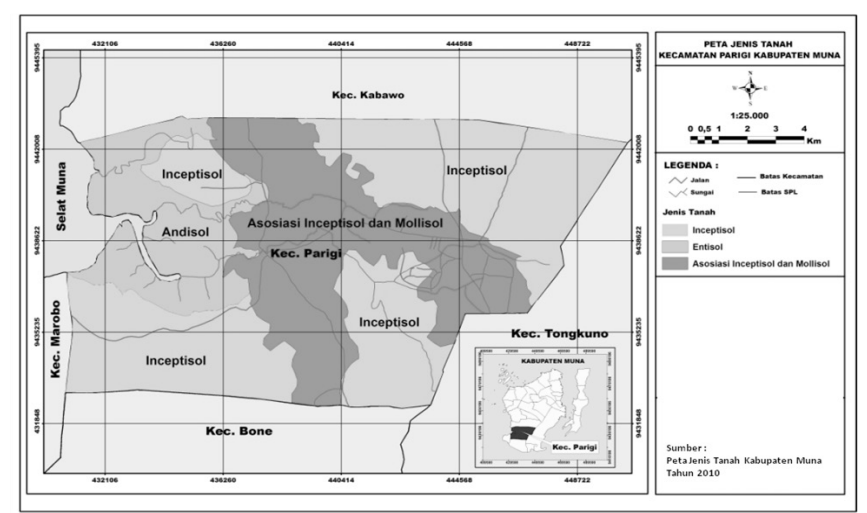

Gambar 1. Peta jenis tanah Kecamatan Parigi Kabupaten Muna

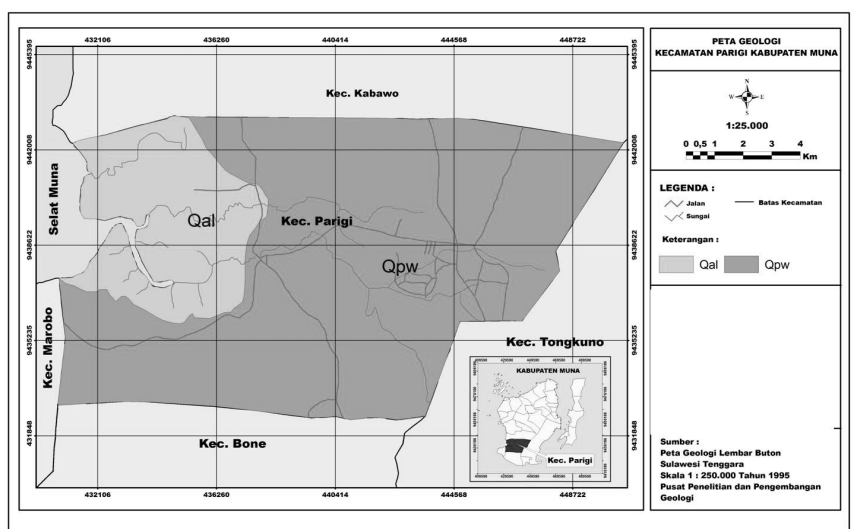

Gambar 2. Peta geologi Kecamatan Parigi Kabupaten Muna

\section{METODE PENELITIAN}

Penelitiaan ini dilaksanakan pada jenis tanah yang berkembang pada daerah karts yaitu tanah Iceptisol, Mollisol dan Andisol di Kecamatan Parigi Kabupaten Muna. Metode yang digunakan dalam analisa neraca air lahan adalah metode Thornthwaite dan Mather (1957). Data masukan yang diperlukan yaitu: curah hujan, evapotranspirasi potensial (ETP), lengas tanah pada tingkat kapasitas lapang (KL) masing-masing jenis tanah, dan kandungan lengas tanah pada tingkat titik layu permanent (TLP) masing-masing jenis tanah.

Prosedur perhitungan neraca air menurut Thornthwaite dan Mather (1957) dengan langkah-langkah sebagai berikut:

1. Curah hujan $(\mathrm{CH})$

Menentukan data curah hujan rata-rata bulanan

2. Evapotranspirasi potensial (ETP)

Menentukan nilai ETP dari stasiun setempat dengan urutan prioritas ETP dengan rumus empiris (Penman Monteith) pada software Cropwat 8.0

3. CH-ETP

Menentukan nilai selisih $\mathrm{CH}$ dengan ETP

4. Akumulasi potensial kehilangan air untuk penguapan (APWL)

Menetukan dengan penjumlahan nilai CH-ETP yang negatif secara berurutan bulan demi bulan.

5. Kandungan lengas tanah (KAT)

Menentukan nilai KAT dimana terjadi APWL dengan rumus:

$\mathrm{KAT}=\mathrm{TLP}+[[1,00041-(1,07381 / \mathrm{AT})]|\mathrm{APWL}| \mathrm{xAT}]$

Keterangan:

TLP: Titik Layu Permanen KL: Kapasitas Lapang Lengas Tersedia $|\mathrm{APWL}|$ : Nilai Absolut APWL

6. Perubahan kadar air tanah (dKAT)

Nilai dKAT bulan tersebut adalah KAT bulan tersebut dikurangi KAT bulan sebelumnya. Nilai positif menyatakan perubahan kandungan lengas tanah yang 
berlangsung pada $\mathrm{CH}>\mathrm{ETP}$ (musim hujan), penambahan berhenti bila dKAT $=0$ setelah KL tercapai. Sebaliknya bila $\mathrm{CH}<$ ETP atau dKAT negatif, maka seluruh $\mathrm{CH}$ dan sebagian KAT di - evapotranspirasikan.

7. Evapotranspirasi Aktual (ETA)

Bila $\mathrm{CH}>$ ETP maka ETA $=$ ETP karena ETA mencapai maksimum. Bila $\mathrm{CH}<\mathrm{ETP}$ maka $\mathrm{ETA}=\mathrm{CH}+|\mathrm{dKAT}|$ karena seluruh $\mathrm{CH}$ dan dKAT seluruhnya akan dievapotranspirasikan.

8. Defisit (D)

Defisit selisih antara nilai Evapotranspirasi potensial (ETP) dan nilai Evapotransiprasi Aktual

9. Surplus (S)

Surplus berarti kelebihan air ketika $\mathrm{CH}<$ ETP sehingga, $\mathrm{S}=\mathrm{CH}-\mathrm{ETP}-\mathrm{dKAT}$, berlangsung pada musim hujan

\section{HASIL DAN PEMBAHASAN}

Pendekatan neraca air memungkinkan untuk mengevaluasi dinamika lengas tanah dan penggunaan air oleh tanaman secara kuantitatif (Lascano, 1991; Brisson dkk., 1992; Lascano, 1991), dan menghitung ketersediaan air secara spasial pada suatu wilayah (Latha dkk., 2010; Tanika, 2013). Ketersediaan air tersebut diilustrasikan dengan tingkat air di lapisan tanah yang berbeda. Kelebihan air atau gravitasi mengalir cepat dari tanah setelah hujan berat karena gaya gravitasi (titik jenuh dengan kapasitas lapangan). Air yang tersedia masih dipertahankan dalam tanah setelah kelebihan telah dikeringkan (kapasitas lapang untuk titik layu) (Imteaz dkk., 2011). Air tersedia adalah kelembapan tanah yang dipegang begitu erat dengan tanah yang tidak dapat diekstraksi oleh tanaman. Air tetap dalam tanah bahkan di bawah titik layu tanaman (Latha dkk., 2010).

Perbedaan jenis tanah akan mempengaruhi kadar lengas tanah pada kapasitas lapang dan titik layu permanen. Neraca air lahan dipengaruhi oleh kapasitas lapang dan titik layu permenen (Brisson dkk., 1992). Tingkat ketersediaan lengas tanah diperoleh dengan menganalisa data kandungan lengas tanah terhadap nilai suhu, dan ETP (Ayu dkk., 2013).

Tabel 1. Kadar air pada kapasitas lapang (KL) dan titik layu permanen (TLP) di berbagai jenis tanah di Kecamatan Parigi

\begin{tabular}{cccc}
\hline Jenis tanah & KL $(\mathrm{mm})$ & TLP $(\mathrm{mm})$ & KAT $(\mathrm{mm})$ \\
\hline Iceptisol & 193,3 & 70,6 & 122,7 \\
Mollisol & 152,1 & 63,3 & 88,8 \\
Andisol & 182,6 & 87,5 & 95,1 \\
\hline
\end{tabular}

Tabel 2. Nilai ETP

\begin{tabular}{lcc}
\hline \multicolumn{1}{c}{ Bulan } & Suhu $\left({ }^{\circ} \mathrm{C}\right)$ & ETP $(\mathrm{mm} /$ hari $)$ \\
\hline Januari & 27,8 & 155,82 \\
Februari & 26,9 & 131,10 \\
Maret & 27,9 & 152,88 \\
April & 27,7 & 144,00 \\
Mei & 28,1 & 153,00 \\
Juni & 27,5 & 142,56 \\
Juli & 27,7 & 146,88 \\
Agustus & 27,3 & 145,23 \\
September & 27,9 & 147,00 \\
Oktober & 27,7 & 151,20 \\
November & 27,2 & 145,23 \\
Desember & 26,7 & 146,28 \\
\hline
\end{tabular}

Sumber: Perhitungan (2016)

Nilai ETP tertinggi terjadi pada bulan Januari yaitu $155,82 \mathrm{~mm} /$ hari dengan suhu rata- rata yaitu $27,8 \mathrm{C}$, sedangkan ETP terendah terjadi pada bulan Februari yaitu $131,1 \mathrm{~mm} /$ hari dengan suhu rata-rata $26,9{ }^{\circ} \mathrm{C}$. Perbedaan nilai ETP ini dipengaruhi oleh faktor iklim dan kedaan kondisi tanah setempat (Moore dkk., 2011; Helena dan Daniel 2012).

Gambar 3 menjukkan bahwa pada bulan Februari, Maret, dan April memiliki nilai curah hujan lebih tinggi dari pada evapotranspirasi potensial yang terjadi. Hal ini menunjukan bahwa pada bulan-bulan ini terjadi surplus air. Pada bulan Mei, Juni, Juli, Agustus, September, Oktober, dan

Tabel 3. Neraca air lahan

\begin{tabular}{lrccc}
\hline \multicolumn{1}{c}{ Bulan } & $\begin{array}{c}\mathrm{CH} \\
(\mathrm{mm})\end{array}$ & $\begin{array}{c}\text { ETA }(\mathrm{mm} / \\
\text { hari })\end{array}$ & $\begin{array}{c}\text { Surplus } \\
(\mathrm{mm})\end{array}$ & $\begin{array}{c}\text { Defisit } \\
(\mathrm{mm})\end{array}$ \\
\hline Januari & 145,97 & 158,57 & & 2,75 \\
Februari & 142,73 & 142,73 & 11,63 & \\
Maret & 157,97 & 157,97 & 5,09 & \\
April & 153,94 & 153,94 & 9,94 & \\
Mei & 136,35 & 122,35 & & 30,65 \\
Juni & 125,98 & 98,98 & & 43,58 \\
Juli & 99,19 & 78,19 & & 68,69 \\
Agustus & 83,59 & 74,59 & & 70,64 \\
September & 98,46 & 93,46 & & 53,54 \\
Oktober & 109,34 & 107,34 & & 43,86 \\
November & 114,81 & 114,81 & & 30,42 \\
Desember & 144,12 & 144,12 & & 2,16 \\
\hline Sumber: Perhitungan $(2016)$ & &
\end{tabular}




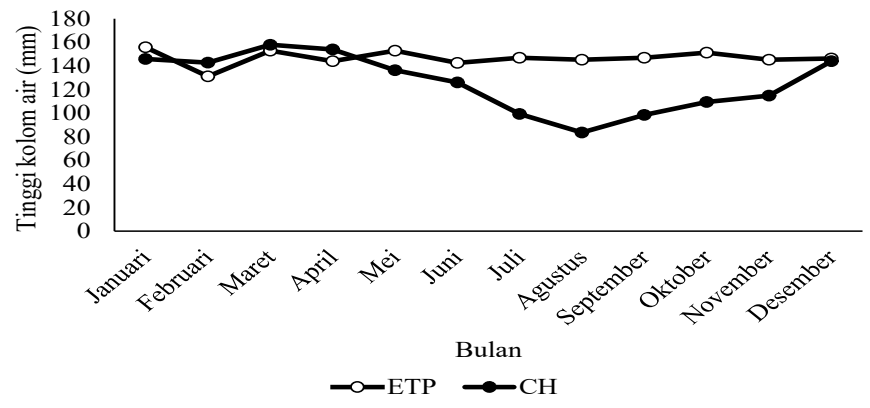

Gambar 3. Neraca air lahan (CH-ETP) di Kecamatan Parigi

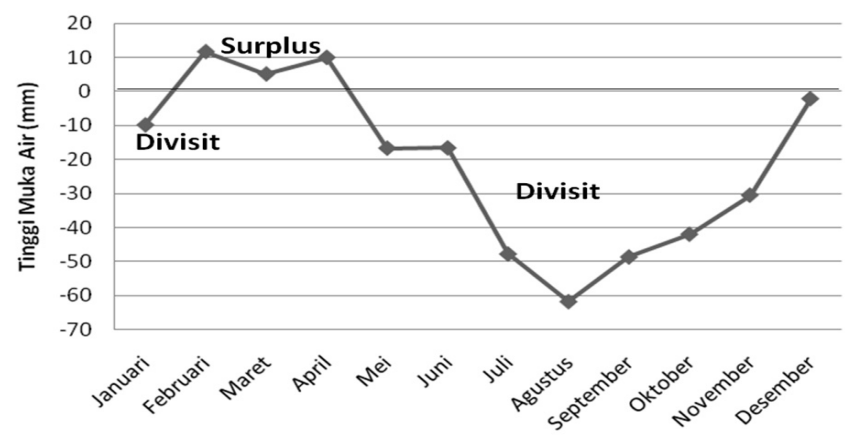

Gambar 4. Neraca air lahan di Kecamatan Parigi

November memiliki nilai evapotranspirasi potensial yang tinggi dibandingkan dengan curah hujan yang terjadi. Hal ini menunjukan bahwa pada bulan-bulan ini terjadi difisit air. Tinggi rendahnya nilai evapotranspirasi yang terjadi berpengaruh terhadap ketersediaan air di dalam tanah (Dugan dan Zelt, 2001; Kobold dkk., 2008; De Miguel dkk., 2012).

Perbedaan kandungan kadar lengas tanah di zona perakaran untuk pertumbuhan tanaman menurun dengan cepat. Hal tersebut disebabkan oleh berbagai faktor diantaranya adalah sifat-sifat fisik tanah. Sifat-sifat fisik tanah di bawahnya, dan selanjutnya berpengaruh terhadap sifat retensi dan pergerakan air dalam tanah (Guerschman dkk., 2009; Latha dkk., 2010; Patrick dkk., 2012; Ayu dkk., 2013).

Berdasarkan hasil analisis neraca air lahan terjadi surplus pada bulan Februari, Maret dan April. Defisit terjadi pada bulan Januari terjadi karena perbedaan antara evapotranspirasi potensial dan aktual. Surplus tertinggi terjadi pada bulan Februari disebabkan oleh beberapa faktor diantaranya kondisi iklim, karateristik lahan serta jenis tanah yang ada di lokasi penelitian. Menurut Lascano (1991), faktor-faktor yang mempengaruhi neraca air lahan yaitu kondisi iklim, keadaan jenis tanah. Perbedaan nilai kapasitas lapangan dan nilai titik layu permanen memberikan pengaruh terhadap ketersediaan air di dalam tanah (Ritchie dkk., 2009; Vanham, 2013).

Faktor dominan yang mempengaruhi neraca air lahan yaitu kondisi iklim setempat (Mehrabadi dkk., 2013) Gambar
4 menunjukkan bahwa pada lahan-lahan yang terbentuk pada daerah karts memiliki nilai divisit air yang tinggi bila dibandingkan dengan surplus air yang terjadi. Salah satu faktor yang mempengaruhi ini adalah kondisi lahan yang terbentuk diatas batuan karts memiliki drainase dibawah tanah yang dominan. Kondisi ini mempengaruhi ketersediaan air untuk tanaman atau pemanfaatan lainnya.

\section{KESIMPULAN}

Neraca air lahan di Kecamatan Parigi yaitu surplus air hujan terjadi pada bulan Februari, Maret dan April, sedangkan divisit air terjadi pada bulan Januari, Mei, Juni, Juli, Agustus, September, Oktober, November, dan Desember. Neraca air lahan dipengaruhi oleh iklim, kondisi lahan dan karateristik tanah.

\section{DAFTAR PUSTAKA}

Ayu. L.W., Sugeng, P. dan Soemarno. (2013). Evaluasi ketersediaan air tanah lahan kering di Kecamatan Unter Iwes, Sumbawa Besar. Jurnal Pembangunan dan Alam Lestari 4: 1 .

Brisson, N., Bernard, S. dan Patrick, B. (1992). Agrometeorological soil water balance for crop simulation models. Agricultural and Forest Meteorology 59: $267-287$.

De Miguel. A., Kallache, M. dan García-Calvo, E. (2012). CWU Model: A water balance model to estimate the water footprint in the Duero river basin. Dalam: Zhang, G.P., Hoekstra, A.Y. dan Tickner, D. (Eds.), Proceedings of the Session Solving the Water Crisis: Common Action Toward a Sustainable Water Footprint, Planet under Pressure Conference, London, 26 March 2012, Value of Water Research Report Series, UNESCO-IHE.

Djakamihardja, A.S. dan Dedi, M. (2013). Implikasi penambangan batugamping terhadap kondisi hidrologi di Citeureup, Kabupaten Bogor, Jawa Barat. Riset Geologi Pertambangan 23: 49-60.

Dugan dan Zelt (2001). Simulation and analysis of soilwater conditions in the Great Plains and adjacent areas, central United States, 1951e80. Reston: U.S. Geological Survey. Water-Supply Paper 2427.

Effendi, A.C., Kusnama dan Hermanto, B. (1995). Peta Geologi Lembar Sultra. Pusat Penelitian dan Pengembangan Geologi, Bandung.

Guerschman, J., Van Dijk, A., Mattersdorf, G., Beringer, J., Hutley, L., Leuning, R., Pipunic, R. dan Sherman, 
B. (2009). Scaling of potential evapotranspiration with MODIS data reproduces flux observations and catchment water balance observations across Australia. Journal of Hydrology 369: 107-119.

Helena Sabo, Daniel Sanislai (2012). Average spillages and water balance in somes plain. International Conference on Environmental Science and Development: 5-7 January 2012, Hong Kong.

Imteaz, M.A., Ahsan, A., Naser dan Rahman, A. (2011). Reliability analysis of rainwater tanks in Melbourne using daily water balance model. Resources, Conservation and Recycling 2011a; 56: 80-6.

Jim Wallace dan Dave McJannet (2012). Climate change impacts on the water balance of coastal and montane rainforests in northern Queensland. Australia Journal of Hydrology 475: 84-96.

Kobold, M., Suselj, K., Polajnar, J. dan Pogacnik, N. (2008), Calibration techniques used for HBV hydrological model in Savinja Catchment. Conference of The Danubian Countries on The Hydrological Forecasting and Hydrological Bases of Water Management.

Lascano, R.J. (1991). Review of models for predicting soil water balance. IAHS Publ 199: 443-458. Lascano, R.J. 2000. A General System to Measure and Calculate Daily Crop Water Use. Journal Agronomy 92: 821-832.

Latha, J., Saravanan dan Palanichamy (2010). A semi distributed water balance model for Amaravathi River basin using remote sensing and GIS. International Journal of Geomatics and Geosciences 1: 252-263.

Mehrabadi, M.H.R., Saghafian, B. dan Fashi, F.H. (2013). Assessment of residential rainwater harvesting efficiency for meeting non-potable water demands in three climate conditions. Resources, Conservation and Recycling 73: 86-93.

Moore, G.W., Jones, J.A. dan Bond, B.J. (2011). How soil moisture mediates the influence of transpiration on streamflow at hourly to interannual scales in a forested catchment. Hydrological Processes 25: 3701-3710.
Noah, M., Schmadel, Bethany T. Neilson, David K. Stevens, (2010). Approaches to estimate uncertainty in longitudinal channel water balances. Journal of Hydrology 394: 357-369.

Patrick, J., Mitchell, Richard G. Benyon, Patrick N.J. Lane (2012). Responses of evapotranspiration at different topographic positions and catchment water balance following a pronounced drought in a mixed species eucalypt forest. Australia Journal of Hydrology 440441: 62-74.

Ritchie, J.T., Porter, C.H., Judge, J., Jones, J.W. dan Suleiman, A. (2009). Extension of an existing model for soil water evaporation and redistribution under high water content conditions. Soil Science Society of America Journal 73 792-801.

Soldevilla-Martineza, M., López-Urrea, R., MartínezMolinab, L., Quemada, M. dan Lizaso, J.I. (2013). Improving simulation of soil water balance using lysimeter observations in a semiarid climate. Procedia Environmental Sciences 19: 534-542.

Suleiman, A.A. dan Ritchie, J.T. (2013). Modeling soil water redistribution during second-stage evaporation. Soil Science Society of America Journal 67: 377-386.

Tanika, L., Chandra, I.W., Elissa, D. dan Ni'matul, K. (2013). Peranan lahan berbasis agroforestri terhadap neraca air di DAS Bialo, Sulawesi Selatan. Prosiding Seminar Nasional Agroforestri hal. 328-334.

Thornthwaite, C.W. dan Matter, J.P. (1957). Instruction and tables for computing potensial evapotranspiration and te water balance. Drexel Institute of Climatology. New Jersey. 401p.

Vanham, D. (2013) An assessment of the virtual water balance for agricultural products in EU river basins Water Resources and Industry 1-2: 49-59.

Zappa, M. dan Gurtz, J. (2003). Simulation of soil moisture and evapotranspiration in a soil profile during the 1999 MAP-Rivera Campaign. Hydrology and Earth System Sciences 7: 903-919. 